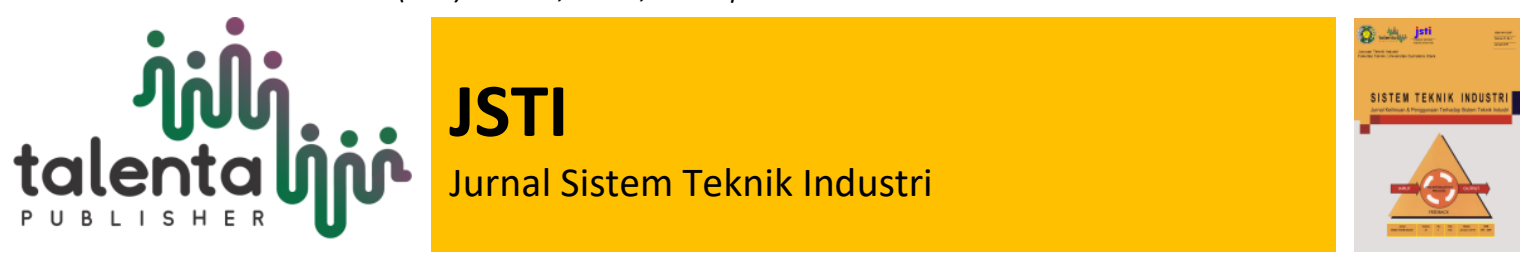

\title{
Optimalisasi Persediaan Bahan Baku Atap Spandex dengan Metode $\mathbf{Q}$
}

\author{
Indah Rizkya ${ }^{1}$, Fernando ${ }^{2}$ \\ ${ }^{1,2}$ Departemen Teknik Industri, Fakultas Teknik, Universitas Sumatera Utara, Medan, Indonesia
}

\begin{abstract}
Inventory management is one of the most important aspects in light steel construction business activities. The application of inventory management affects the continuity of the production process and improves the quality of service to consumers. Inventory is defined as an asset which includes goods owned by the company and has the potential to be sold within a certain business period in an effort to meet consumer needs at any time. Galvalume raw material inventory for the spandex roof production process often suffers from shortages due to immature planning. The shortage of inventory causes production not to run smoothly. The purpose of inventory management in this paper is to obtain an inventory policy to optimize the total inventory cost. The method used in this study is economic order quantity. Based on the results and discussion. Ordering raw materials will be made 6 times in a year with an order quantity of 116 with a safety stock of 12 units and will be ordered again when the raw materials are in 46 units. Total Inventory Cost (TIC) which was originally IDR 26.350 .191 ,- can be saved to IDR 21.038 .827 ,- so that the total savings that occurred amounted to IDR 5.311.364,- $(20,15 \%)$.
\end{abstract}

Keyword: Inventory Management, Q Method, Economic Order Quantity, Light Steel Construction.

\begin{abstract}
Abstrak. Manajemen persediaan adalah salah satu aspek terpenting dalam kegiatan bisnis konstruksi baja ringan. Penerapan manajemen persediaan berpengaruh pada kelangsungan proses produksi dan meningkatkan kualitas pelayanan kepada konsumen. Persediaan diartikan sebagai aset yang meliputi barang-barang yang dimiliki oleh perusahaan dan berpotensi untuk dijual dalam jangka waktu bisnis tertentu dalam upaya pemenuhan kebutuhan konsumen setiap saat. Persediaan Bahan baku galvalume untuk proses produksi atap spandex sering mengalami kekurangan akibat perencanaan yang belum matang. Kekurangan persediaan menyebabkan produksi tidak berjalan lancar. Tujuan pengelolaan persediaan pada paper ini untuk mendapatkan kebijakan persediaan untuk mengoptimalkan total biaya persediaan. Metode yang digunakan dalam penelitian ini adalah kuantitas pesanan ekonomi. Berdasarkan hasil dan pembahasan. Pemesanan bahan baku dilakukan sebanyak 6 kali dalam 1 tahun dengan jumlah pemesanan 116 dengan safety stock 12 unit dan akan dipesan kembali saat bahan baku berjumlah 46 unit. Total Inventory Cost (TIC) yang semula Rp. 26.350.191,- dapat dihemat menjadi Rp. 21.038.827,- sehingga total penghematan yang terjadi sebesar Rp. $5.311 .364,-(20,15 \%)$.
\end{abstract}

Kata Kunci: Manajemen Persediaan, Metode Q, Economic Order Quantity, Konstruksi Baja Ringan.

Received 20 November 2020 | Revised 10 January 2021 | Accepted 19 January 2021

*Corresponding author at: Jalan Almamater Kampus USU Medan 


\section{Pendahuluan}

Persediaan merupakan aset yang dimiliki perusahaan dan memiliki peran penting dalam kelangsungan bisnis perusahaan, sehingga perlu dilakukan pengelolaan yang proaktif. Perusahaan harus memiliki kebijakan untuk mengantisipasi kondisi kekurangan persediaan. Tantangan dalam pengelolaan persediaan bertujun untuk mencapai total biaya penanganan persediaan yang minimal [1]. Manajemen persediaan merupakan salah satu aspek terpenting dalam kegiatan bisnis konstruksi baja ringan. Penerapan manajemen persediaan berpengaruh pada berlangsungnya proses produksi. Kosongnya persediaan dapat menghambat jalannya proses produksi. Proses produksi yang berjalan lancar akan meningkatkan kualitas pelayanan. Persediaan diartikan sebagai aset yang dimiliki oleh perusahaan seperti barang-barang yang berpotensi untuk dijual dalam jangka waktu bisnis tertentu dalam upaya pemenuhan kebutuhan konsumen setiap saat. Manajemen persediaan bertujuan untuk mewujudkan keuntungan bagi perusahaan melalui optimasi biaya persediaan dan menghindari kekurangan bahan [2].

Persediaan biasanya dalam bentuk bahan baku, barang setengah jadi, dan produk akhir [3]. Persediaan dapat menyokong terlaksananya kelancaran produksi, namun persediaan dengan jumlah besar menyebabkan tingginya biaya produksi. Persediaan bahan baku perlu untuk mengantisipasi ketidak pastian dalam proses produksi dan dalam pengiriman bahan baku oleh supplier. Persediaan diperlukan untuk memenuhi kebutuhan selama waktu tunggu. Persediaan juga dimaksudkan untuk merespon permintaan konsumen yang fluktuatif [4]. Untuk itu penting bagi perusahaan melakukan pengendalian terhadap jumlah persediaan. Pengendalian persediaan membantu tercapainya suatu tingkat efisiensi dalam pengelolaan biaya perusahaan. Pengendalian persediaan mampu mengatasi kekurangan bahan dalam proses produksi namun biaya persediaan minimum. Metode $\mathrm{Q}$ atau yang sering dikenal dengan Economic Order Quantity berusaha mencapai tingkat persediaan optimal dan mampu meminimalkan stockout, sehingga tidak mengganggu proses produksi. Pengendalian persediaan sangat perlu dilakukan untuk mencegah terjadinya kekurangan persediaan. Kebijakan yang tepat dalam mengelola persediaan akan mengurangi biaya persediaan. [5].

Salah satu perusahaan yang bergerak dalam pembentukan lembaran baja menjadi Baja Ringan mengalami kekurangan bahan baku atap spandeks yang berupa kumparan galvalume. Kekurangan persediaan menyebabkan proses produksi terhambat karena bahan baku tidak tersedia pada saat dibutuhkan. Selama ini, sistem pemesanan bahan baku dilakukan sebulan sekali secara rutin dengan jumlah yang yang bervariasi, tanpa perencanaan sehingga terjadi kekurangan bahan pada saat tertentu yang menghambat proses produksi. Belum adanya perencanaan yang matang dalam hal pemesanan bahan baku yang akan diproduksi dapat menghambat proses produksi dan juga menimbulkan kerugian jika tidak direncanakan dengan optimal. Paper ini akan menggambarkan perencanaan persediaan bahan baku atap spandex yaitu galvalume sehingga diperoleh kebijakan pemesanan bahan baku yang optimal. 


\section{Tinjauan Pustaka}

Persediaan didefinisikan sebagai aset lancar perusahaan dapat berbentuk barang ataupun peralatan yang dapat disimpan untuk digunakan atau dijual pada periode mendatang guna mendukung kegiatan operasional perusahaan. Persediaan yang digunakan untuk mendukung kegiatan produksi, digolongkan dalam tiga jenis, yaitu (1) Persediaan bahan baku, bahan tambahan dan bahan penolong, (2) persediaan barang setengah jadi (work in progress/WIP) dan (3) persediaan produk akhir/barang jadi. Kesalahan dalam menentukan ukuran persediaan berdampak pada timbulnya permasalahan seperti terganggunya aktivitas produksi sehingga tidak terpenuhinya permintaan kosumen. Disisi lain kelebihan persediaan menyebabkan barang disimpan terlalu lama di dalam Gudang sehingga biaya penyimpanan meningkat atau habisnya masa berlaku produk.

Pengendalian persediaan merupakan suatu kegiatan pengendalian terhadap jumlah pembelian dan persediaan untuk bahan baku, barang work in proggress, dan barang jadi dengan maksud agar proses produksi berjalan lancar [6]. Pengendalian persediaan bertujuan untuk (1) menjaga keberlangsungan aktivitas produksi sehingga perusahaan tidak mengalami kekosongan persediaan yang berakibat pada terhentinya proses produksi, (2) menghindari pembelian barang dalam jumlah kecil, karena dapat berdampak pada meningkatnya biaya pesan, dan (3) memenuhi kebutuhan konsumen dengan cepat khususnya pada persediaan produk akhir.

Optimasi persediaan bertujuan untuk mengefisiensikan biaya produksi seperti biaya pemesanan bahan, biaya penyimpanan bahan, biaya kerusakan produk akibat terlalu lama disimpan, dll. Persediaan optimal dicapai melalui keseimbangan factor jumlah produk, permintaan konsumen, periode produksi, fasilitas gudang/tempat penyimpanan dan biaya simpan, daya tahan produk, biaya kekurangan persediaan serta resiko lain yang muncul akibat adanya persediaan. Salah satu metode yang dapat digunakan untuk mengendalikan persediaan baik itu bahan baku, barang setengah jadi, ataupun produk jadi adalah metode Q atau yang dikenal dengan metode Economic Order Quantity (EOQ).

Metode Economic Order Quantity (EOQ) digunakan untuk membantu para pelaku bisnis mengelola persediaannya agar tidak mengalami kerugian. Metode ini pertama kali dikembangkan oleh Fird Haris dan R.H. Wilson secara terpisah pada Tahun 1915. Metode EOQ ini merupakan salah satu model deterministik yang mempertimbangkan dua biaya dasar dalam persediaan yaitu biaya pemesanan dan biaya penyimpanan [9]. Biaya pemesanan adalah seluruh biaya yang dikeluarkan untuk melakukan pemesanan kepada pihak vendor sedangkan biaya penyimpanan adalah biaya yang dikeluarkan untuk menyimpan satu unit produk. Oleh karena itu, Total Inventory Cost (TIC) adalah penjumlahan biaya pemesanan dan biaya penyimpanan. Metode EOQ juga digunakan sebagai alat untuk mengontol stok dalam penyimpanan dengan cara mempertahankan jumlah dasar permintaan tetap pada saat tingkat persediaan memasuki titik kritis $[6,7]$. 
Pengendalian persediaan dengan metode EOQ telah banyak dilakukan. Manajemen persediaan dengan metode EOQ telah diimplementasikan pada industry bahan bangunan oleh Juwari. Metode EOQ digunakan untuk memperkirakan jumlah permintaan konsumen dan jumlah yang harus dipesan secara optimal. Sehingga dapat diketahui informasi mengenai jumlaha persedian dan jumlah yang harus dipesan serta biaya yang dibutuhkan [7]. Penelitian lain dilakukan pada industry proyek [8]. Permasalahan yang muncul pada saat pelaksanaan proyek terdapat persediaan material yang tidak ada sama sekali atau malah sebaliknya terjadi penumpukan kelebihan material di gudang. Untuk menghindari masalah tersebut, perlu dilakukan upaya pengaturan mekanisme pengendalian material pada saat pelaksanaan proyek. Penelitian ini akan menjelaskan tentang penerapan pengendalian persediaan material yang efektif diterapkan oleh perusahaan. Dari hasil penelitian ditemukan penurunan biaya persediaan setelah menerapkan metode Economic Order Quantity [4].

Metode EOQ digunakan untuk menentukan jumlah pemesanan optimal (paling ekonomis) untuk memenuhi kebutuhan pelanggang [9]. Pengetahuan mengenai permintaan konsumen melalui peramalan dijadikan dasar untuk mempertimbangkan tingkat permintaan konsumen akan persediaan barang. Sehingga penerapan metode EOQ dalam mengelola persediaan mampu persediaan seperti biaya pemesanan dan biaya penyimpanan. Berdasarkan studi yang telah dilakukan sebelumnya, metode Economic Order Quantity dapat digunakan sebagai solusi atas permasalahan kekurangan material dan memberikan keuntungan bagi perusahaan. Makalah ini menggambarkan pengelolaan persediaan bahan baku menggunakan metode EOQ untuk mengatasi masalah kekurangan persediaan bahan baku pada salah satu industri baja ringan.

\section{Metodologi Penelitian}

Permasalahan yang dibahas dalam paper ini terjadi di salah satu industry baja ringan di Sumatera Utara. Pendekatan yang digunakan adalah pendekatan kuantitatif menggunakan data sekunder yang diperoleh dari dokumen perusahaan. Beberapa data sekunder yang diperoleh yaitu data jumlah galvalume coil yang digunakan, biaya pemesanan, biaya tenaga kerja, biaya pemeliharaan Gudang, biaya kepemilikan aset Gudang, dll.

Model EOQ dapat digunakan apabila (1) permintaan terhadap produk diketahui, (2) pola datangnya permintaan konstan, (3) harga produk per unit tidak mengalami perubahan, (3) biaya penyimpanan pertahun tetap/konstan untuk setiap unit produk, (4) biaya pemesanan per pesanan tetap/konstan (5) leadtime (waktu pesanan dibuat hingga pesanan diterima) diketahui dengan pasti, dan (6) tidak ada kekurangan barang atau pesanan kembali [8].

Metode EOQ dilakukan dengan mengikuti langkah-langkah sebagai berikut:

1. Perhitungan Total Inventory Cost pada kondisi yang berjalan diperusahaan. Total inventory cost pada kondisi existing digunakan sebagai pembanding hasil usulan dengan metode Economic Order Quantity (EOQ). Pada existing condition ini, dilakukan perhitungan variable-varibel yang dibutuhkan seperti biaya pemesanan dan biaya penyimpanan produk galvalume. 
2. Perhitungan Total Inventory Cost, pada langkah ini kita menghitung total kebutuhan bahan baku (D) biaya pemesanan per pemesanan (S), holding cost per unit bahan baku (H), rata-rata pembelian bahan baku (Q) untuk menghitung total persediaan biaya (TIC).

3. Perhitungan metode kuantitas pesanan ekonomi. Pada langkah ini kita menghitung pembelian bahan baku dengan jumlah ekonomis $\left(\mathrm{Q}^{*}\right)$ yang akan dihitung, frekuensi pembelian $(\mathrm{F})$, total biaya persediaan (Total Inventory Cost/TIC), persediaan pengaman (Safety stock/SS) dan tingkat pemesanan kembali (Reorder Point/ROP).

\section{Hasil dan Pembahasan}

\subsection{Total Biaya Persediaan}

Sebelum menghitung total biaya persediaan terlebih dahulu kita perlu menghitung total kebutuhan bahan baku (D), biaya pesan per pemesanan (S), biaya penyimpanan per periode per unit bahan baku $(\mathrm{H})$, dan rata-rata pembelian bahan baku (Q). Tabel 1 menunjukkan jumlah galvalume coil yang digunakan selama 12 periode bulanan dari September 2019 hingga Agustus 2020.

Tabel 1 Jumlah Kumparan Galvalume yang digunakan

\begin{tabular}{cc}
\hline Periode & $\begin{array}{c}\text { Jumlah material yang } \\
\text { digunakan (unit) }\end{array}$ \\
\hline $09-2019$ & 57 \\
$10-2019$ & 60 \\
$11-2019$ & 57 \\
$12-2019$ & 59 \\
$01-2020$ & 59 \\
$02-2020$ & 57 \\
$03-2020$ & 56 \\
$04-2020$ & 53 \\
$05-2020$ & 55 \\
$06-2020$ & 59 \\
$07-2020$ & 57 \\
$08-2020$ & 58 \\
\hline Total & 687 \\
\hline Rata-rata & 57,5 \\
\hline
\end{tabular}

Biaya pemesanan adalah seluruh biaya yang muncul akibat proses pengadaan barang dari luar. Biaya pemesanan meliputi biaya yang dikeluarkan untuk melakukan order, biaya ekspedisi, biaya komunikasi, biaya korespondensi, pengeluaran untuk fotokopi dan perlengkapan administrasi lainnya, biaya unloading, biaya inspeksi pada proses penerimaan dan atau pengiriman, serta biaya handling ke gudang [9]. Total biaya pemesanan selama 1 tahun sebesar Rp. 21.200.000,- dengan rincian biaya telfon Rp. 2.400.000,- biaya pengiriman Rp. 16.800.000,- dan biaya administrasi sebesar Rp. 2.000.000,-. Biaya pemesanan untuk setiap pemesanan (S) adalah:

$$
\begin{aligned}
\text { Biaya pemesanan }(\mathrm{S}) & =\frac{\text { Total Ordering Cost }}{\text { Ordering frequency }} \\
& =\frac{21.200 .000}{12} \\
& =\text { Rp. } 1.766 .667
\end{aligned}
$$


Biaya simpan atau holding cost adalah biaya-biaya yang muncul karena adanya proses penyimpanan suatu barang. Biaya simpan tersebut antara lain: biaya kepemilikan (capital cost), biaya gudang, biaya akibat kerusakan dan penurunan nilai pada saat penyimpanan, biaya kadaluarsa, biaya asuransi, biaya administrasi dan transfer [9]. Total biaya simpan selama satu tahun sebesar RP 125.270.000,-

$$
\text { Biaya simpan per unit bahan baku } \begin{aligned}
(\mathrm{H}) & =\frac{\text { Total Holding Cost }}{\text { Total material requirement }} \\
& =\frac{125.270 .000}{687} \\
& =\mathrm{Rp} .182 .343,-
\end{aligned}
$$

Total kebutuhan bahan baku (D) 687 unit dengan rata-rata pembelian bahan baku (Q) 57,5 unit, biaya pemesanan (S) Rp 1.766.667/ sekali pesan dan biaya penyimpanan per unit (H) Rp 182.343,. Sehingga total biaya persediaan yaitu:

$$
\begin{aligned}
\text { Total biaya persediaan } & =\frac{\mathrm{SD}}{\mathrm{Q}}+\frac{\mathrm{HQ}}{2} \\
& =\frac{(1.766 .667 \times 687)}{57,5}+\frac{(182.343 \times 57,5)}{2} \\
& =\text { Rp. } 26.350 .191,-
\end{aligned}
$$

Total biaya persediaan yang menjadi beban perusahaan sebesar Rp. 26.350.191,- untuk setiap periode pemesanan.

\subsection{Pengendalian Persediaan dengan Economic Order Quantity}

Pengendalian persediaan menggunakan metode $\mathrm{Q}$ yang harus dilakukan adalah menghitung kuantitas pemesanan bahan baku ekonomis $\left(\mathrm{Q}^{*}\right)$, kemudian frekuensi pembelian bahan baku $(\mathrm{F})$, Total Biaya Persediaan (TIC) ekonomis, stok pengaman (SS) dan titik pemesanan kembali (ROP). Jumlah pemesanan bahan baku optimal $\left(\mathrm{Q}^{*}\right)$ diperoleh dengan menggunakan persamaan:

$$
Q^{*}=\sqrt{\frac{2 \mathrm{DS}}{\mathrm{H}}}
$$

Q* adalah kuantitas pemesanan optimal untuk sekali pesan. Jumlah pesanan diluar nilai pada Q* memungkinkan terjadinya peningkatan total biaya persediaan. Dimana D adalah jumlah kebutuhan dalam setahun, S adalah biaya yang dikeluarkan setiap kali melakukan pemesanan, dan $\mathrm{H}$ adalah biaya untuk menyimpan setiap unit barang. Jumlah pemesanan galvalume coil yang optimal adalah:

$$
\mathrm{Q}^{*}=\sqrt{\frac{2 \times 687 \times 1.766 .667}{182.343}}=115,4 \approx 116 \text { unit }
$$

Jumlah pemesanan optimal sebesar 116 unit per sekali pesan. Sehingga frekuensi pemesanan (D/Q*) dalam setahun adalah 6 kali. Dengan metode Economic Order Quantity, total biaya persediaan adalah: 


$$
\begin{aligned}
\text { TIC } & =\frac{\mathrm{SD}}{\mathrm{Q}}+\frac{\mathrm{HQ}}{2} \\
& =\frac{(1.766 .667 \times 687)}{116}+\frac{(182.343 \times 116)}{2} \\
& =\text { Rp. } 21.038 .827,-
\end{aligned}
$$

Metode EOQ menghasilkan total biaya persediaan (TIC) lebih rendah dibandingkan kebijakan perusahaan selama ini dari Rp. 26.350.191,-. menjadi Rp. 21.038.827,-. Sehingga metode EOQ ini layak untuk digunakan di perusahaan guna mengendalikan persediaan bahan baku atap spandex yaitu galvalume coil.

\subsection{Safety Stock dan Reorder Point}

Persediaan pengaman atau safety stock adalah persediaan yang dibuat dengan tujuan untuk mengatasi lonjakan permintaan selama leadtime akibat kesalahan dalam melakukan perkiraan permintaan. Jika permintaan yang datang melebihi perkiraan rata-rata permintaan tersebut maka persediaan pengaman tersebut digunakan. Jumlah persediaan pengaman yang harus disedikan perusahaan bergantung pada faktor ketidakpastian permintaan dan pemenuhan persediaan. Standar deviasi leadtime digunakan untuk mewakili faktor ketidakpastian pemenuhan persediaan. Standar deviasi permintaan digunakan untuk mewakili faktor ketidakpastian persediaan. Leadtime merupakan waktu yang dibutuhkan untuk memenuhi persediaan, dari mulai pesanan dibuat hingga barang diterima perusahaan. Apabila kedua foktor tersebut (permintaan dan leadtime) diketahui dan besarannya konstan, maka persediaan pengaman tidak dibutuhkan [10].

Persamaan untuk menentukan persediaan pengaman, yaitu:

$$
\text { Safety Stock }=\mathrm{Z} \times \mathrm{Sd} \times \sqrt{\mathrm{L}}
$$

Dimana $\mathrm{Z}$ adalah Service level perusahaan, Sd adalah standar deviasi permintaan, dan L adalah lead time pemesanan. Persediaan pengaman untuk memenuhi lonjakan permintaan selama leadtime adalah:

$$
\begin{aligned}
\text { Safety Stock } & =1,65 \times 1,87 \times \sqrt{14} \\
& =11,544 \approx 12 \text { unit }
\end{aligned}
$$

Kebijakan persediaan dengan metode EOQ memberikan informasi jumlah pemesanan optimal. Selain itu perlu untuk mengetahui titik waktu kapan pemesanan harus dilakukan kembali (reorder point). Perusahaan melakukan pesanan tidak boleh menunggu persediaan habis. Apabila permintaan datang pada waktu tunggu pesanan tiba (leadtime) maka permintaan tersebut tidak dapat dilayani (stockout) dan keberlanjutan produksi juga terganggu. Titik pemesanan kembali (reorder point) merupakan saat yang paling tepat dimana perusahaan melakukan pemesanan kembali. Tujuannya agar pesanan tiba persediaan digudang belum habis. Persamaan perhitungan titik pemesanan kembali, yaitu:

$$
\mathrm{U}=\frac{\mathrm{D}}{\text { jumlah hari kerja }}
$$




$$
=\frac{687}{287}=2,39 \text { units/day }
$$

Kemudian titik pemesanan kembali dihitung sebagai berikut:

$$
\begin{aligned}
\text { Reorder Point } & =(\mathrm{U} \times \mathrm{L})+\mathrm{SS} \\
& =(2.39 \times 14)+12 \\
& =45,46 \approx 46 \text { unit }
\end{aligned}
$$

Perusahaan harus melakukan pemesanan kembali, saat persediaan telah mencapai jumlah 46 unit. Jumlah pemesanan yang dilakukan setiap kali pesan adalah 116 unit.

\section{Kesimpulan}

Berdasarkan hasil dan pembahasan diatas Pemesanan bahan baku akan dilakukan sebanyak 6 kali dalam 1 tahun dengan jumlah pemesanan 116 dengan safety stock 12 unit dan akan dipesan kembali pada saat bahan baku berjumlah 46 unit. Total Biaya Persediaan (TIC) yang semula Rp. 26.350.191 dapat dihemat menjadi Rp. 21.119.275, sehingga total penghematan yang terjadi menjadi sebesar Rp. 5.311.364,- yaitu sebesar 20,15\%.

\section{DAFTAR PUSTAKA}

[1] M. C. Tuerah, "Analisis Pengendalian Persediaan Bahan Baku Ikan Tuna Pada CV. Golden K" Jurnal EMBA vol. 2 no.4, pp. 524-536, 2014.

[2] F. Rangkuti, “Manajemen Persediaan" Jakarta: PT Rajagrafindo Persada, 2000.

[3] M. R. Suryanto dan A. Sadjiarto, "Efisiensi Penggunaan Model EOQ (Economic Order Quantity) Pada PT. Puspa Madu Sari Salatiga" Among Makarti vol. 5 no. 10, pp 110-134, 2012.

[4] I. Rizkya et al, "Comparison of Periodic Review Policy and Continuous Review Policy for the Automotive Industry Inventory System" in IOP Conf. Ser.: Mater. Sci. Eng. 288012085 , 2018.

[5] I. Rizkya et al, "Determination of Inventory Policy based on ABC Classification" in IOP Conf. Ser.: Mater. Sci. Eng. 851 012014, 2020.

[6] A. Sofyan. 2008, Produksi dan Manajemen Operasi. Edisi revisi. Jakarta: Fakultas Ekonomi, Universitas Indonesia.

[7] Juwari, Kusrini, dan P. Eko, "Analisis Sistem Inventory Manajemen Dengan Metode Economic Order Quantity (EOQ)" Junal Sistem Informasi Ilmu Komputer Prima vol. 2 no, pp. 33-40, 2018.

[8] H. Tannady dan K. Filbert, "Pengendalian Persediaan Dengan Menggunakan Metode Economic Order Quantity dan Silver Meal Algorithm (Studi Kasus PT SAI)" Jurnal Teknik dan Ilmu Komputer vol. 07 no. 25, 2018.

[9] N. K. D. A. Jayanti dan L. P. A. Prapitasari, "Penerapan Metode EOQ (Economic Order Quantity) Pada Peramalan Stok Barang" Proceedings Konferensi Nasional Sistem dan Informatika (KNS\&I), 2015.

[10] I. N. Pujawan, Supply Chain Management. Surabaya: PT Guna Widya, 2005. 